\title{
História para educadores: o objeto de estudo da área de História
}

\author{
Adreana Dulcina Platt
}

Departamento de Educação da Universidade Estadual de Londrina (UEL-PR);

Pós-doutora em Ciências Humanas pela Universidade Federal de Santa Catarina (UFSC-SC); adplatt@uel.br

\section{Resumo}

Dispostas em particulares disciplinas, as áreas expressam especificos olhares voltados a "produção da humanidade" em cada sujeito (Saviani, 1991). Tal realidade tem sua "gênese" e desenvolvimento na divisão do trabalho "manual" e "intelectual". Ao desenharmos a relevância do que será apreendido em cada área do conhecimento para a formação de amplas e seguidas gerações, partimos ao anúncio do objeto de estudo dos saberes norteadores das práticas produtivas, culturais e técnico-cientificas marcados num determinado tempo e lugar históricos, e expostos institucionalmente numa carta curricular. Pautados nessa perspectiva, elegemos a área de História para investigarmos seu objeto de estudo. Selecionamos um universo de 103 docentes da disciplina de História da rede de ensino em Londrina/PR (Brasil) para responderem questões sobre o específico desta área. Sistematizados os dados, compilamos os resultados apoiados no método de Análise de Conteúdo de Bardin (2004). Seguindo a proposta, organizamos os dados conforme a frequência das respostas, elegendo as palavras com conteúdo categorial significativo para a área e conforme sua maior incidência. Pelos resultados, aduzimos introdutoriamente uma convergência nas respostas pela identificação de um objeto significativamente descrito na regularidade discursiva, ou seja, ofoco a ser perseguido por certa geração de professores na defesa epistêmica da área de estudo pela temática: o homem no tempo. Da mesma forma, o estudo identifica certas tendências, socialmente determinantes -veiculadas em academias e programas de capacitação-, e relevantes, enquanto fonte de análise, para o reconhecimento do eixo praxiológico de área do conhecimento condutor de uma dada racionalidade curricular.

\section{Palavras-chave}

Educação, currículo, história, objeto de área, análise de conteúdo. (Fonte: Tesauro da Unesco).

Recepción: 2013-04-12 / Envío a pares: 2014-01-27 / Aceptación por pares: 2014-03-20 / Aprobación: 2014-04-07 DOI: 10.5294/edu.2014.17.2.3

Para citar este artículo / To reference this article / Para citar este artigo

Dulcina Platt, A. (2014). História para educadores: o objeto de estudo da área de História. Educ. Educ. 17 (2) 254-268. Doi 10.5294/ edu.2014.17.2.3 


\title{
History for Educators: The Object of Study in the Field of History
}

\begin{abstract}
Arranged in particular disciplines, areas express specific ways of looking at the "production of humanity" in each subject (Saviani, 1991). This reality has its "genesis" and development in the division between "manual" and "intellectual" labor. In considering the relevance of what is to be grasped in every area of knowledge for the formation of broad and subsequent generations, we start with announcement of the object of study of the knowledge that guides the productive, cultural and technical - scientific practices set in a particular historical time and place, and displayed institutionally in a curriculum. Here, we have chosen the field of history to investigate the object of its study. In doing so, we selected a universe of 103 history teachers from the school system in Londrina, Parana (Brazil) to answer questions on the specifics of this area. Having systematized the data, we compiled the results using Bardin's content analysis method (2004). Following this approach, we organized the data according to the frequency of the responses, selecting the words with significant categorical content for the area and with major incidence. Given the results, we adduce, in an introductory way, a convergence in the responses through the identification of an object significantly described in the regular discourse; that is, the central object of interest to be pursued by a certain generation of teachers in epistemic defense of the area of study on the subject: man in time. The study also identifies certain socially determinant trends - conveyed in academia and advanced courses -that are relevant as a source of analysis for recognizing the praxeological crux of the area of knowledge guiding a given curricular rationale.
\end{abstract}

Key words

Education, curriculum, history, area object, content analysis. (Source: Unesco Thesaurus). 


\title{
Historia para educadores: el objeto de estudio del área de historia
}

\author{
Resumen
}

Dispuestas en disciplinas particulares, las áreas expresan visiones especificas dirigidas a la "producción de la humanidad" en cada sujeto. Esta realidad tiene su génesis $y$ desarrollo en la división del trabajo manual e intelectual. Al trazar la importancia de lo que será aprendido en cada área del conocimiento para la formación de amplias y futuras generaciones, partimos del anuncio del objeto de estudio de los saberes que guiarán las prácticas productivas, culturales y técnico-científicas marcadas en determinado tiempo y lugar histórico, y expuestos en el currículo. Desde esa perspectiva, elegimos el área de Historia para investigar su objeto de estudio. Seleccionamos un universo de 103 docentes de esta disciplina pertenecientes a la red de enseñanza de Londrina/PR (Brasil) para que respondieran preguntas especificas de esta área. Una vez sistematizados los datos, reunimos los resultados apoyados en el método de Análisis de Contenido de Bardin. Con base en la propuesta, organizamos los datos de acuerdo con la frecuencia de las respuestas, eligiendo las palabras con contenido categorial significativo para el área y conforme a su mayor incidencia. A la par con los resultados presentamos la convergencia de las respuestas para identificar algún objeto significativo descrito regularmente en el discurso, o sea, el foco perseguido por cierta generación de profesores en la defensa epistemológica del área de estudio para la temática: el hombre en el tiempo. Así mismo, el estudio identifica ciertas tendencias socialmente determinantes - transmitidas en programas de capacitación-, y relevantes en cuanto fuente de análisis, para el reconocimiento del eje praxiológico del área de conocimiento conductora de una determinada racionalidad curricular.

\section{Palabras clave}

Educación, curriculo, historia, objeto del conocimiento, análisis de contenido. (Fuente: Tesauro de la Unesco). 


\section{Introdução}

A constituição curricular leva sobre si o papel organizador de toda a atividade pedagógica, o que permite inevitavelmente a visibilidade de uma determinada rotina formativa que se dá no tempo e espaço (Saviani, 1991). Na modernidade, essa formação tem se caracterizado incisivamente por um eixo "instrumental" dos sujeitos, justificado no ideário de preparação dos sujeitos para o enfrentamento de novos e complexos formatos de produção e, consequentemente, sociais. Esse aspecto denuncia o princípio legitimador de uma sistematização dos conhecimentos dispostos curricularmente com vistas à construção de uma "rotina formativa".

Somada à construção reiterada de um "cotidiano", reconhecemos toda a existência social (amplo sentido) se realizando e se reproduzindo por movimentos históricos por meio da "assimilação das relações sociais" possiveis a partir das oportunidades de "mediações entre o indivíduo e os costumes" (Heller, 1989, pp. 18-19). Essas mediações configurarão o "ser genérico" do indivíduo, que afirma e expressa a história da produção humana no tempo e espaço integrando-o numa "consciência de nós" (Heller, 1989, p. 21).

Se o currículo aponta os conhecimentos acumulados e relevantes à formação político-social (cultural) e produtiva de uma sociedade, deve-se considerar sua vanguarda ao reconhecimento dos processos de apropriação técnico-científica e produtiva alcançado pela humanidade. Da mesma forma, o currículo serve ao papel de catalisador dessa etapa de desenvolvimento (técnico-científico) com vistas à preparação das novas e contínuas gerações:

Na produção social da sua vida os homens entram em determinadas relações, necessárias, independentes da sua vontade, relações de produção que correspondem a uma determinada etapa de desenvolvimento das suas forças produtivas materiais. A totalidade destas relações de produção forma a estrutura econômica da sociedade, a base real sobre a qual se ergue uma superestrutura jurídica e política, e à qual correspondem determinadas formas de consciência social. O modo de produção da vida material é que condiciona o processo da vida social, politica e espiritual. (Marx, 1982, pp. 530-531).

Na modernidade, reconhecemos o papel da especialização como característica preponderante nos processos de formação social e pautados em conhecimentos cada vez mais operacionais. O parcelamento da atividade produtiva em nichos infinitamente específicos também marcará as demais relações sociais de uma maneira profunda. Se verificarmos o esforço da humanidade contemporânea em responder por sua existência na modernidade, concluiremos que apenas em "estado neurótico" é possivel demonstrar a eficiência arguida pelos novos paradigmas de produção e reprodução da vida (Braverman, 1977, p. 87). Assim, o atual vetor para a formação de homens e mulheres aponta objetivamente para um modelo ajustado no cálculo de: tempo de formação reduzido + apreensão de habilidades especificas + internalização (institucional e individual) de uma politica meritocrática (Lessa, 1998).

A escola, enquanto instituição com legitimidade social, responde pela produção e reprodução dos conhecimentos sistematizados e epistêmicos à sociedade civil vinculada à construção de sua rotina na formação de gerações de sujeitos que compreendam sua constituição humana genérica num sentido praxiológico (Vázquez, 1977). Esse empreendimento se constitui e se dissemina em conformidade às forças sociais que dominam e veiculam seus discursos, no tempo e espaço, para uma formação genérica dos sujeitos.

Saviani (2002) assegura que o Brasil, por exemplo, aliou produtividade e escolarização desde os primeiros movimentos de consolidação da atividade industrial no país, sendo que essa "visão produtivista da educação" tem se materializado enquanto política pública apenas entre as décadas de 1950 e 
1970. No final de 1980, encontramos políticas de formação que se alcunham com o cálculo acima descrito e confirmado pela seguinte análise:

Sob a inspiração do toyotismo busca-se flexibilizar e diversificar a organização das escolas e o trabalho pedagógico, assim como as formas de investimento. Em ambos os periodos, prevalece a busca pela produtividade guiada pelo principio de racionalidade que se traduz no empenho em se atingir o máximo de resultado com o mínimo de dispêndio. (Saviani, 2002, p. 23).

Com isso, podemos considerar os saberes da produção originalmente desvinculados de um "trabalho criador" (trabalho artesanal), o que torna os sujeitos despossuídos de uma consciência dialética da organização social. Ou seja, ainda que a organização da produção industrial seja uma resposta irremediável à demanda que se multiplica na velocidade de uma progressão geométrica, há de se falar numa formação humana voltada à internalização dessa lógica produtiva com desdobramentos que se voltam à gestação de uma específica organização e formação sociais enquanto pressupostos à "manutenção da ordem vigente" (Saviani, 2002), especialmente assentados nos princípios liberais e na produção capitalista.

Esses dados oferecem pistas sobre os conhecimentos considerados relevantes e a serem apreendidos para a construção de rotinas para a formação dos sujeitos na modernidade, uma vez destinadas à reificação dos valores originais de uma "sociedade" que repousa sobre a urgente resposta às "necessidades de mercado". Nesse ínterim, podemos ainda pontuar as revoluções científicas como instrumentos corroboradores para o recrudescimento de uma mentalidade social capitalista, já que são respostas objetivas às descobertas oriundas de um determinado momento do desenvolvimento industrial.

A ciência deve infinitamente mais à produção. As necessidades da produção, da prática social, fixam tarefas à ciência e impõem certo caráter ao seu desenvolvimento, aos problemas que elaboram nas diversas etapas da história. O desenvolvimento da produção cria as condições materiais e as técnicas das descobertas cientificas, põe entre as mãos dos pesquisadores os meios de experiência necessários. Finalmente, é o desenvolvimento da produção que determina o método geral prevalecente na Ciência. É preciso também levar em conta a luta de classes e da ideologia dominante. (Fataliev, 1966, p. 35).

Devemos considerar, neste universo de elementos, a posição dos saberes que antes se inscreviam como "armas" nas mãos dos filósofos iluministas para a insurreição contra os poderes despóticos e absolutistas de determinados monarcas, mas que, neste momento, serão reorientados para a gestão científica da produção e reorganização dos aparelhos de Estado ao visar à veiculação de uma nova conformação social, coligidos pelos interesses do capital.

\section{As possiveis contradições dos conhecimentos na modernidade: saber pragmático para uma formação plena?}

Diante do que acima debatemos, encaminhamos um estudo no qual nos questionamos: dentre os saberes escolhidos em cada período histórico para a formação dos sujeitos, o que se destacaria de seu conjunto temático para ser considerado "imprescindível" à "produção da humanidade" no outro (Saviani, 1991)?

Essa pergunta tem nos perseguido há algum tempo.

O foco dos conhecimentos voltados a uma formação humana plena e ao gozo daquilo que se reconhece enquanto possibilidades formativas e críticas dos sujeitos (em detrimento aos saberes pragmáticos reduzidos a um "consumo imediato" ou circunscrito a algum aspecto da cultura escolar) tem sido nosso esforço investigativo nestes últimos anos. 
O estudo ao objeto de cada área do conhecimento significa deter-se na materialização de uma perspectiva cuja proposta vislumbra a problematização de cada disciplina/conhecimento a partir de seu elemento mais pulsante: a especificidade de seu objeto de estudo ante uma "constelação" de temáticas que gravitam ao seu redor, assim como nas demais disciplinas, e sempre voltadas à formação humana plena. Isso significa dizer que nos debruçaremos na apreensão de conhecimentos não vinculados imediatamente a "valores de troca" —como um excedente a ser vendido-, mas voltado ao desenvolvimento omnilateral ${ }^{1}$ dos sujeitos. Outrossim, ao desenharmos a relevância do que será apreendido em cada área do conhecimento para a formação de amplas e seguidas gerações, partimos inexorável e obstinadamente ao anúncio do objeto de estudo dos saberes que norteiam as práticas produtivas, culturais e técnico-científicas, que se marca dos elementos de um determinado tempo e lugar históricos, e exposto institucionalmente numa carta curricular.

A proposta indica a problematização dos saberes que compreendem a rotina formativa escolar com a intenção de ressignificá-la enquanto campo da epistemologia educacional.

Há de se considerar que a escola comporta a existência de um largo e bem sucedido "programa de assimilação aos costumes" (Durkheim, 2010). Esse programa tem o propósito de levar os sujeitos a apreenderem os códigos que os tornam "genéricos" ou "universais" em relação aos demais "sujeitos do mundo", reproduzindo essa forma homogênea de existência desvelada em movimentos particulares (construídos na rotina da vida).

1 Perspectiva omnilateral/omnidimensional (omni: todo, lateral: lado; dimensional: dimensão). Conforme Manacorda (1991, p. 81) "a omnilateralidade é a chegada histórica do homem a uma totalidade de capacidades produtivas e, ao mesmo tempo, a uma totalidade de capacidades de consumo e prazeres, em que se deve considerar, sobretudo o gozo daqueles bens espirituais, além dos materiais, e dos quais o trabalhador tem estado excluído em consequência da divisão do trabalho".
Nesse contexto, o modelo ideal de educação escolarizada se torna refém de um grave descompasso existente entre as expectativas voltadas à apreensão de conhecimentos relevantes à hegemonia da produção capitalista e às exigências do seu desenvolvimento técnico-científico, em detrimento dos conhecimentos dirigidos à formação de sujeitos tais como "produtos e produtores históricos de humanidade" (Saviani, 1991; 2002).

Ainda que a produção em larga e acelerada escala (modelo industrial) seja uma resposta oportuna à demanda e ao grau de complexidade conquistado pela humanidade no período moderno (Vázquez, 1977), não desconsideraremos neste estudo que os múltiplos saberes e suas especificidades, embora voltadas às práticas formativas, não devem se distanciar de um projeto educacional contra-hegemônico, cuja proposta pedagógica esteja alcunhada de rigores críticos e históricos (Saviani, 1991; Duarte, 1999).

O estudo ao objeto das diferentes áreas do conhecimento tem o propósito de intervir neste momento crítico-reflexivo das práticas pedagógicas. Essa perspectiva assenta-se na construção de movimentos sustentados na práxis dialética que visam à construção do cotidiano escolar (ou de uma rotina formativa).

Dispostas em particulares disciplinas, as áreas expressam específicos olhares que estão dirigidos à "produção da humanidade" em cada sujeito (Saviani, 1991). Tal realidade tem sua "gênese" e desenvolvimento na divisão do trabalho "manual" e "intelectual". Marx (1982, p. 23) assim dispõem:

A divisão do trabalho só se torna efetivamente divisão do trabalho a partir do momento em que se opera uma divisão entre o trabalho material e o trabalho espiritual. A partir deste momento, a consciência pode de fato imaginar que é algo mais do que a consciência da prática existente, que ela representa realmente algo, sem representar algo real (grifos nossos). 
Para Engels (1979, p. 5),

La investigación empirica de la naturaleza ha acumulado una masa tan gigantesca de conocimientos de orden positivo, que la necesidad de ordenarlos sistemáticamente y ateniéndose a sus nexos internos, dentro de cada campo de investigación, constituye una exigencia sencillamente imperativa e irrefutable. Y no menos lo es la necesidad de establecer la debida conexión entre los diversos campos de conocimiento. El pensamiento teórico de toda época, incluyendo por tanto la nuestra, es un producto histórico, que reviste formas muy distintas y asume, por tanto, un contenido muy distinto también, según las diferentes épocas².

O autor nos relata uma importante verdade sobre a evolução dos conhecimentos: o processo industrial tem particular responsabilidade pelas novas formas de conquista e apropriação de matéria-prima, o que significa reconhecer novas possibilidades de alteração da realidade objetiva pelos novos instrumentais colocados à disposição da ciência (matéria-prima entendida como elemento indispensável ao desenvolvimento do pensamento científico e tecnológico). Outro aspecto reiteradamente sustentado por Engels será o vínculo dos conhecimentos circunscritos em uma "evolução histórica do pensamento humano. As ideias que em diferentes períodos da história se formam sobre as conexões em geral do mundo exterior, e que constituem também uma necessidade para a ciência no sentido conceitual quando nos serve como critério para contrastar as teorias por elas formuladas" (Engels, 1979, p. 9).

2 "A investigação empírica da natureza tem acumulado um volume tão imenso de conhecimentos de ordem positiva, que a necessidade de ordená-los sistematicamente atendose a seus nexos internos, dentro de cada campo de investigação, constitui uma exigência simplesmente imperativa e irrefutável. Não menos é a necessidade de estabelecer a devida conexão entre os diversos campos do conhecimento. O pensamento teórico de toda época, incluindo, portanto a nossa, é um produto histórico que possui formas bem distintas e assume, portanto, um conteúdo bem distinto segundo as diferentes épocas." (tradução livre).
Dessa forma, o estudo sobre o objeto de cada área do conhecimento não pode se furtar a análise de seu tempo e dos determinantes que orientam a vida material e imaterial dos sujeitos.

Apoiando-nos nesta assertiva procederemos à descrição dos movimentos que nos levaram à análise desse fenômeno/objeto a partir de dados coletados numa amostra da realidade.

\section{O objeto de estudo da área de História: reconhecimento do núcleo epistêmico da disciplina de História a partir da atividade docente}

\section{A investigação ao objeto de estudo da História: investigar qual realidade?}

Fernandes (1967, p. XVII) considerava as ciências sociais e humanas como "ciências novas". Por certo, essa percepção o fazia reconhecer as dificuldades metodológicas que delas adviriam. Diferentemente do exercício epistêmico orientado precipuamente pelos procedimentos científicos requeridos nas ciências naturais (como a observação — considerada instrumento suficiente para a descrição da realidade), as "ciências novas" procuraram um trajeto que lhes proporcionassem, da mesma forma, a outorga científica, ainda que muitos de seus dados se constituíssem de categorias com lastro imaterial.

O desafio das ciências sociais e humanas a partir dessa premissa será a "reconstrução empírica da realidade", que significa apreender "o que os fatos representam nos contextos empíricos de que fazem parte" (Fernandes, 1967, p. 8). Após a representação desses fatos (no contexto em que se inserem), segue-se a "navalha" da análise para a constatação científica do estudo. Segundo o autor (p. 8), esse cuidado ocorre pelo fato de a realidade sensível (imediata) não nos permitir essa apreensão "de forma direta", o que se constitui imediatamente como 
"guia à nossa capacidade de percepção e intelecção do próprio mundo em que vivemos".

No desvelamento da realidade proporcionado pelo estudo, serão "agrupadas as instâncias empíricas coligidas e reconstruídos os fenômenos sociais observados, quanto a seus elementos, a suas propriedades e às condições de sua manifestação" (Fernandes, 1967, p. 24). A condição desse exercício investigativo se pautará precipuamente na convergência dos elementos que revelam as características do fenômeno/objeto. Entretanto, o autor assevera que a "reprodução da realidade" não significará o absoluto espelhamento de todos os elementos constituídos na "vida social":

Apenas são retidos e fundamentados empiricamente os aspectos que mantém alguma relação estrutural ou funcional com a organização do sistema social tribal e com a persistência dele como um todo. (...). Ele não visa explicar os efeitos de uma série especial de fatores, mas como os fatores atuantes em um sistema social dado, com os efeitos correspondentes, se combinam entre si em certas condições de tempo e de espaço e contribuem para determinar a forma de integração e o grau de estabilidade do sistema como um todo. Daí resulta que esse tipo de conhecimento constitui uma transcrição abstrata do concreto. (Fernandes, 1967, p. 30 - grifos nossos).

Quando nos propomos a investigar o objeto de estudo da área de História, sistematizamos uma versão que operacionalizasse a identificação de dados retirados da realidade objetivamente. Por meio dessa perspectiva metodológica, entendemos a possibilidade de apropriação do objeto de estudo que parte de um "chão" de assertivas: a realidade (contexto), enquanto uma "totalidade", e seus elementos particulares ("múltiplas determinações" que se constituem sensivelmente na rotina da existência) igualmente "totais". A análise será possível se extrairmos do contexto (realidade total) "determinado elemento, isolá-lo, examiná-lo” (Netto, 2011, p.44).
Neste extrato de múltiplas determinações do contexto (realidade total), constituem-se material, histórica e dialeticamente uma "dimensão ontológica" (constituída pela matéria enquanto unidade que não prescinde à consciência dos sujeitos) e uma "dimensão gnosiológica" da existência humana (Triviños, 1995, p. 53), ou seja, implica descrevê-la como aspecto que materialmente responde pela existência humana entendida como processo histórico (portanto, de transformação da realidade e das relações sociais e de produção), objetivamente implicado no desenvolvimento de uma "teoria do conhecimento", numa consciência "sobre" e "do" mundo.

A investigação ao objeto da disciplina de "História", elemento integrante de formação constituído no currículo escolar ou área do conhecimento das ciências humanas, implicou o debate sobre a constituição de um saber que não parte do "vazio", da pura abstração mecanicista.

Se a prática é critério da verdade objetiva para o materialismo dialético, daí não se segue a confusão deste com alguma espécie de pragmatismo. Trata-se de transformar o mundo. Mas a transformação do mundo implica e pressupõe a interpretação correta deste mesmo mundo. (Gorender apud MarX, 1998, p.XXXVII - Introdução).

Assim, parte-se do elemento elaborado pelos sujeitos sociais e suas determinadas circunstâncias com vistas à "transformação do mundo" que implica e pressupõe, por si, a interpretação correta (ou aproximada, porquanto constituída de variadas possibilidades interpretativas) desse mesmo mundo.

Para a descrição do objeto de estudo da História -área do conhecimento curricular-, empreendemos o recorte (total) da realidade (total) que seria analisada. Orientamos este momento a partir de alguns pressupostos:

1. Circunscrevemos o município de Londrina e região como o locus para a coleta de dados; este foi o campo onde desenvolvemos os estudos 
específicos dessa área do conhecimento. Esse aspecto delimitou o exercício desse "saber" às universidades, escolas e institutos que se encontram na região.

2. O universo da amostra nesses espaços institucionais foram os pesquisadores e professores de História que estivessem em pleno exercício das atividades de ensino.

3. Escolhemos o questionário como instrumento para a coleta dos dados como dispositivo de memória, registro direito, possível a revisitações. Havia unicamente duas questões "abertas" no instrumento:

- Qual o objeto de estudo da área de História? e

- Quais os objetivos que você tem para o desenvolvimento da disciplina ao longo do ano?

4. Desse universo selecionado, foram coletados e respondidos 103 questionários.

Essas premissas possuem justificativas de orientação aos elementos selecionados para a sistematização dos dados.

\section{a. Quanto ao locus para coleta da amostra}

Fernandes (1967, p. 3) asserta que "aspectos essenciais dos fatos ou fenômenos investigados são obtidos, selecionados, coligidos em "totalidades coerentes" para o domínio técnico da investigação científica". Um dos fatores dessa coerência está na escolha de um "contexto empírico" que forneça dados consistentes sobre o objeto de estudo. Entendemos que o locus desta pesquisa reproduz as características e propriedades do "fenômeno concreto no estado em que ele é considerado"3, o que permite o

3 Sobre as variantes regionais: estas serão consideradas no momento da análise dos dados. É importante salientar, no entanto, que entendemos a existência de certo lastro na formação do historiador que possivelmente ultrapassa graves diferenças regionais principalmente motivadas pelo âmbito da formação universitária e pelas associações de classe (a Associação Nacional de Pesquisa em História - tratamento dos dados mediante sua ocorrência. Reconhecemos a presença de instituições educacionais no município e região (como universidades, escolas e institutos) enquanto apoios suficientes para a representação analítica do contexto empírico aludido pelo autor (Fernandes, 1967, p. 39). Esse dado não obstaculizaria inferências e apoios investigativos quanto a outras realidades totais deste objeto de estudo.

\section{b. Quanto ao universo selecionado para aplicação do instrumento de pesquisa}

Nossa proposta selecionou o universo de 100 professores e/ou pesquisadores, atuantes, da área de História do município de Londrina e região, por dois motivos. O primeiro responde à tentativa de considerarmos um volume de sujeitos quantitativamente superior ao recorte usual das pesquisas qualitativas —ainda que reconhecidamente não absoluto em relação aos professores computados da rede estadual e municipal (pública ou privada)-. Propomos, na verdade, o desafio de ouvir o número expressivo de "vozes" desses profissionais, reconhecendo-os na construção de uma rotina que se apoia no exercício reiterado das atividades formativas a partir do reconhecimento ao objeto de estudo da área que atuam (no caso, de História).

O segundo motivo será a coleta de dados circunscrita aos profissionais que se encontravam em plena atividade do magistério e/ou de pesquisa. Esse aspecto se justifica na necessária atualização de dados da realidade pesquisada uma vez reconhecida a existência dos programas de capacitação em serviço dos profissionais do magistério -instrumento que permite o diálogo com a contemporaneidade dos temas de área, e inevitavelmente com seu objeto de estudo, enquanto pressuposto da atuação institucional-. A investigação ao objeto de determinada área do conhecimento exige do profissional seu re-

ANPUH-, por exemplo), que divulgam e reconhecem entre os pares os principais eixos para a formação nacional desse profissional. 
conhecimento sobre o acúmulo das questões e estudos pertinentes a essa disciplina formativa.

\section{c. Quanto ao uso do questionário com duas perguntas "abertas" como instrumento para a coleta dos dados}

Em orientações a pesquisadores, Rummel (1977, p. 103) recomendava o uso do questionário em estudos que investigassem o "status de práticas correntes e na direção de sondagens de opiniões e de levantamento de atitudes". Da mesma forma, o autor alertava sobre o mau uso desse instrumento, principalmente quanto a questões equivocadas e ambíguas, que tornavam o instrumento ineficaz em seu propósito.

Lakatos e Marconi (1982), ao verificarem as vantagens e desvantagens desse instrumento para coleta de dados, elencam um número maior de aspectos positivos que negativos do procedimento. O processo de elaboração desse instrumento, segundo as autoras, deve receber maior atenção do pesquisador para evitar os desvios de finalidade: "exige cuidado na seleção das questões, levando em consideração a sua importância, isto é, se oferece condições para a obtenção de informações válidas" (Lakatos, Marconi, 1982, p. 76). Segundo a classificação clássica (Severino, 2000; Lakatos, Marconi, 1982; Rummel, 1977, entre outros), o questionário utilizado nesta pesquisa teve duas questões abertas ("livres ou não limitadas"), as quais esperavam do universo investigado dados de opinião própria para que a investigação obtivesse respostas "profundas e precisas" para análise. Ouanto à forma, as questões enunciadas não expressavam alternativas positivas ou negativas, mas cogitavam a existência de um objeto de estudo de área.

Na elaboração do roteiro levou-se em conta o referencial teórico e a realidade social do objeto da pesquisa. Entende-se que o roteiro deve consistir numa tradução dos aspectos fundamentais norteadores do estudo. Assim, construiu-se um conjunto de itens e questões abertas que orientaram os vários procedimentos de coleta de informações (Damasceno 1986, p. 41-grifos nossos).

Nossa preocupação se voltou a um elenco de dados que poderiam denunciar o objeto de estudo da área de História pelo profissional questionado. Estávamos cientes, outrossim, de que essa questão poderia representar um dado novo na percepção do questionado (professores de História) quanto a uma especificidade de área não refletida anteriormente, mesmo durante sua formação acadêmica. Prevenimo-nos desse possivel resultado apoiados na importante observação de Marx e Engels (1998, p. 11): "A maneira como os indivíduos manifestam sua vida reflete exatamente o que eles são. O que eles são coincide, pois, com sua produção, isto é, tanto com o que eles produzem". Dessa forma, seria possível racionalizar que reduziríamos o equívoco com a delimitação do universo de amostra aos sujeitos que se encontrassem em pleno desenvolvimento da atividade do magistério. Isso geraria um menor campo de especulações, de digressões, pela perspectiva de que o próprio exercício profissional manteria o sujeito centrado em seu objeto de estudo nas apropriações conceituais continuamente exigidas pela dinâmica escolar.

A questão apresentada aos professores enunciava:

- Qual o objeto de estudo de sua área de conhecimento (específico não encontrado em nenhuma outra disciplina).

Pretendíamos com essa pergunta:

- $\quad$ suscitar um raciocínio operacional sobre o objeto da disciplina;

- $\quad$ o reconhecimento e a descrição próprios sobre a especificidade da área.

No estudo ao questionário elaborado por Marx, Ferreira (2004, p. 6) apresenta os aspectos que cercamos em nossa pesquisa: 
Nesse sentido, o questionário é muito mais um roteiro para reflexão e discussão sobre o trabalho que um instrumento para captar respostas a serem tabuladas. Diferente em relação à "não neutralidade" do autor. Suas questões não são aleatórias nem independentes entre si, mas se encadeiam, respeitando uma linha de raciocinio que o autor quer, voluntariamente, passar. É clara a sua intenção de fazer o leitor pensar e se questionar sobre sua própria condição e sua própria ignorância em relação a ela.

A descrição do objeto de área a partir de uma racionalidade construída pelo professor no lastro de seu exercício profissional também se respalda na fundamentação teórica que utilizamos neste estudo:

De acordo com Florestan (Fernandes), o conhecimento cientifico explicativo pode ser em si mesmo revolucionário se, ultrapassando e contrariando o senso comum e as representações dominantes, for capaz de atingir os nexos profundos, determinações da realidade, que regulem a ocorrência dos fenômenos característicos das questões cruciais socialmente. (Cardoso, 2012, p. 93 - grifos nossos).

Enfim, a estratégia para coleta de dados junto a professores tinha a perspectiva de não nos distanciarmos da construção de uma rotina epistêmica escolar (singularmente enquanto objeto do Currículo) e que ao mesmo tempo denunciasse outros eixos que compõem o mapa amplo de formação social: formação acadêmica, exercício profissional e elaboração didático-pedagógica e política.

\section{Os resultados da pesquisa}

Durante a distribuição dos questionários, tivemos o cuidado de apresentarmos o instrumento ao docente e esperar pelo preenchimento no local. A relação do aplicador com o pesquisado se limitava a responder-lhe quando arguido sobre as diferenças entre as categorias "objeto" e "objetivo". Essa dinâmica nos proporcionou sucesso no número de retornos, o que dirimiu o tempo disponível para outras fases do estudo. Assim, dos questionários distribuídos, obtivemos o retorno de 103 questionários. Tabulados os dados, apresentamos os resultados obtidos.

Com a descrição das respostas coletadas, amplas análises podem ser tecidas. No entanto, nosso compromisso neste estudo se circunscreve à sistematização e apresentação das palavras-chave reconhecidas nessa tabela de frequência pela verificação de sua incidência nos questionários. Esse elemento será importante para o posterior debate sobre as unidades de conteúdo encontradas. A análise dessa frequência foi observada pelo número reiterado (repetido) considerado ao máximo de respostas idênticas dadas pelos professores (Bardin, 2004).

Embora os dados demonstrem certa convergência nas respostas, a identificação de um objeto de área apresentado como, por exemplo, na palavrachave: "o homem" (encontrado em 9 questionários), ou na palavra-chave: "o homem no tempo" (encontrado em 13 questionários), significativamente deve ser considerada para a apreciação de certa objetividade discursiva que pode alterar uma racionalidade epistêmica curricular —ou seja, o foco perseguido por certa geração de professores na defesa epistêmica da área de estudo- assim como podem denunciar as tendências sociais amplas - principalmente em acadêmicas e programas de capacitação que circunscrevem à formação de professores em pleno exercício do magistério-.

Partimos do pressuposto que uma alteração de racionalidade epistêmica curricular deva ocorrer motivada pela garantia do pleno exercício e função social da escola, tese defendida por Saviani (1991), quando afirma que o currículo é "o desenvolvimento das atividades nucleares da escola". Se a atividade nuclear da escola é de natureza epistêmica, o objeto de cada área do conhecimento tem seu pressuposto na e pela ciência (embora compreendida enquanto exercício humano objetivo e encharcada de pretensões, ideologias e instrumentalidades disponiveis ou não para seu exercício e realização). 
Tabela 1. Tabulação do léxico reincidente nos dados coletados

\begin{tabular}{|c|c|}
\hline O homem & 9 \\
\hline Fato histórico & 7 \\
\hline O homem e a sociedade & 5 \\
\hline O homem no tempo & 13 \\
\hline A localização do homem no processo histórico & 1 \\
\hline Perspectivas históricas e sociais & 1 \\
\hline Os feitos dos povos no tempo e espaço & 6 \\
\hline As transformações em cada período histórico & 2 \\
\hline A origem e evolução do ser humano no tempo & 3 \\
\hline O tempo & 5 \\
\hline Análise e coleta de fontes & 5 \\
\hline O passado - a memória & 5 \\
\hline Organização, produção de cultura e os conflitos sociais no tempo & 2 \\
\hline A produção humana & 3 \\
\hline Os feitos do passado para a civilização moderna & 1 \\
\hline Formação da identidade do sujeito e a história de sua cultura & 2 \\
\hline A cultura de um povo & 1 \\
\hline Estudo da construção e transformação do conhecimento humano & 1 \\
\hline Os acontecimentos ocorridos ao longo do tempo & 2 \\
\hline A construção da história da humanidade & 2 \\
\hline As ações e transformações realizadas pelo homem ao longo do tempo & 2 \\
\hline Temporalidade & 3 \\
\hline Construção da identidade social (ou de um povo) & 3 \\
\hline Desenvolvimento das nações & 1 \\
\hline Tempo e espaço & 1 \\
\hline O sujeito como produtor cultural & 1 \\
\hline A sociedade, a religiosidade e a política nas diferentes idades. & 1 \\
\hline As mudanças trazidas pelo "devir histórico" às relações humanas e estruturas sociais & 1 \\
\hline O desenvolvimento da humanidade & 1 \\
\hline Total & 89 \\
\hline
\end{tabular}

Tabela 2. Respostas que não especificaram o tema proposto

\begin{tabular}{|l|c|}
\hline $\begin{array}{l}\text { As implicações humanas no processo histórico; as relações temporais/espaciais; aspectos econômicos, políticos, } \\
\text { sociais e culturais da humanidade. }\end{array}$ & 2 \\
\hline Ampliação da visão de mundo (daquele que aprende) & 2 \\
\hline A história & 2 \\
\hline Desigualdade social & 1 \\
\hline Áreas afins (Relação entre Estado, sociedade e política pública; literatura) & 2 \\
\hline Formação para o senso crítico & 3 \\
\hline Desconexo: "A história faz parte de um todo..." “se dá através do estudo didático associado às atividades culturais”. & 2 \\
\hline Total & 14 \\
\hline
\end{tabular}


Tabela 3. Frequência semântica do léxico selecionado

\begin{tabular}{|l|c|}
\hline O homem & 9 \\
\hline Fato histórico & 7 \\
\hline O homem no tempo & 13 \\
\hline Os feitos dos povos no tempo e espaço & 6 \\
\hline
\end{tabular}

A filosofia da práxis, enquanto referência teórica para pensar a escola pública num projeto de mudanças sociais profundas, abrange várias concepções a respeito não só de quem faz a história, mas também de como e em que instância social ela se faz. (Patto, 1993, p. 122).

Essa alteração, na verdade, deve ser apreciada enquanto elemento rico e presente nas dinâmicas escolares dialógicas e, assim, se revestir de uma "mobilização intelectual" (Charlot, 2007).

Da mesma forma, as pretensões formativas, tanto acadêmicas quanto as relacionadas aos programas de capacitação em serviço, são denunciadas nos dados coletados através do caminho epistêmico escolhido para acolchoar os discursos voltados à formação coletiva em uma especialidade, no tempo e no espaço. Nelas será possível identificar as tendências científicas que gravitam na formação de gerações de estudiosos e especialistas de cada área do conhecimento. Assim, a seleção ou a omissão de certa categoria central ao núcleo epistêmico de uma área do conhecimento por parte do pesquisado nos credencia a verificar que sua escolha provavelmente não tenha sido aleatória, mas justifica-se pelas tendências formativas disponíveis aos sujeitos no tempo e espaço.

Finalmente, a análise dos dados aponta que as respostas conferem aos nossos pressupostos teóricos validade epistemológica, uma vez que o estudo sobre o objeto de cada área do conhecimento não pode se furtar à "análise de seu tempo e dos determinantes que orientam a vida material e imaterial dos sujeitos" (Marx, 1982, p. 7), porquanto a alta frequência presente nas respostas apontam elemen- tos que denunciam o processo de formação docente/acadêmica, inicial e continuada, dos profissionais situados na condição de universo investigado.

\section{Considerações finais}

Os resultados obtidos pela sistematização dos 103 questionários aplicados a professores/pesquisadores, que se encontram em pleno exercício do magistério, ao ministrarem a disciplina de História da região de Londrina/PR, apresentaram importantes indicativos para a continuidade dos estudos sobre a formação desses professores. O estudo demonstra introdutoriamente a tênue linha que separa as linhas epistêmicas que definem o objeto da área no tempo e lugar dessa formação, assim como sugere a continuidade desta investigação agora em relação à conjuntura sociopolítica e econômica que operacionaliza os determinantes para o recorte de conhecimentos epistêmicos veiculados pela instituição escolar e exigidos enquanto categorias imprescindíveis para a análise crítica da realidade.

A respeito dos resultados deste estudo, verificamos certa confusão por parte dos questionados em interpretar o que seria "o objeto de uma área de estudo" e determinar quais seriam os "objetivos propostos para o desenvolvimento da disciplina". Ainda que o aplicador do instrumento estivesse presente, o questionado insistia no equívoco. $\mathrm{Na}$ interpretação dos resultados também aduzimos que, pela maior frequência de respostas dadas à questão n. 1 ("Qual o objeto de estudo da área de História"), a saber, "O homem" (presente em 9 questionários), "Fato histórico" (presente em 7 questionários), "O homem no tempo" (presente em 13 questionários) e "Os feitos dos povos no tempo e espaço" (presente em 6 questionários), os dados demonstram certa convergência nas respostas, pois identificam um objeto de área significativamente descrito na regularidade discursiva (elemento relevante para a possivel alteração de uma racionalidade epistêmica curricular) —ou seja, o foco a ser perseguido por cer- 
ta geração de professores na defesa epistêmica da área de estudo- . Finalmente, pelos dados também podemos identificar as possíveis tendências socialmente determinantes, principalmente em academias e programas de capacitação, destacadamente aos programas dirigidos à formação de professores que se encontram em pleno exercício do magistério, porquanto considerados uma importante fonte de análise sobre o eixo praxiológico e condutor de uma dada racionalidade curricular.

\section{Referências}

Bardin, L. (2004). Análise de Conteúdo. Lisboa: Ed. 70.

Braverman, H. (1977). Trabalho e Capital Monopolista: a degradação do trabalho no século XX. Rio de Janeiro: Zahar.

Cardoso, M. L. (2003). Florestan Fernandes: a criação de uma problemática. Página visitada em 17 de janeiro de 2013 a partir de: http://www.scielo.br/scielo.php?Pid=S0103-40141996000100014\&script=sci_arttext

Charlot, B. (2007). O sujeito e a relação com o saber. Página visitada em 17 de janeiro de 2013 a partir de: http:// www.ice.edu.br/TNX/storage/webdisco/2007/11/22/outros/f64eoo895a14fe18eeg4201beg20739o.pdf

Damasceno, M. N. (1986). Questões teóricas e práticas da pesquisa social e educacional. Em Aberto, Brasília, ano 5, n. 31, jul./set. 1986. Página visitada em 17 de janeiro de 2013 a partir de: http://www.rbep.inep.gov.br/ index.php/emaberto/article/viewfile/2236/1504

Duarte, N. (1999). A individualidade para-si: contribuição a uma teoria histórico-social da formação do indivíduo. 3 ed. Campinas: Autores Associados.

Durkheim, É. (2010). Educação e Sociologia. São Paulo: Hedra.

Engels, F. (1979). Dialéctica da la Naturaleza. México: Grijalbo.

Fataliev, K. (1966). O Materialismo Dialético e as Ciências da Natureza. Rio de Janeiro: Zahar.

Fernandes, F. (1967). O Dilema Educacional Brasileiro. Em: L. Pereira \& M. M. Foracchi (Orgs.) Educação e Sociedade: leituras de sociologia da educação (pp. 414-441). São Paulo: Companhia Editora Nacional.

Ferreira, L. L. (2004). À propos de l'enquête ouvrière. Sobre a enquete operária de 188o, de Karl Marx. 12. Travailler 2004/2. Página visitada em 20 de janeiro de 2013 a partir de: http://www.cairn.info/resume.php?ID_ ARTICLE=TRAV_012_0011

Heller, A. (1989). O Cotidiano e a História. Rio de Janeiro: Paz e Terra.

Lakatos, E. M. \& Marconi, M. A. (1982). Metodologia do Trabalho Científico. São Paulo: Atlas.

Lessa, S. (1998). Marx, Lukács, trabalhadores e proletariado. Página visitada em 22 de janeiro de 2013 a partir de: http://www.sergiolessa.com/CapLivroo8/mrx_lkcs_classes_2008.pdf 
ISSN 0123-1294 | Educ.Educ. Vol. 17. No. 2 | Mayo-Agosto de 2014 | pp. 254-268.

Universidad de La Sabana | Facultad de Educación

Manacorda, M. A. (1991). Marxe a pedagogia moderna. São Paulo: Cortez; Autores Associados.

Marx, K. (1982). Feuerbach: oposição das concepções materialista e idealista. Em: J. Barata-Moura; E. Chitas; F. Melo \& A. Pina (Orgs). Marx \& Engels: obras escolhidas (pp. 9-33). Tomo I. Lisboa, Portugal: “Avante!”: Moscovo, URSS: Progresso.

Marx, K., Engels, F. (1998). A Ideologia Alemã. São Paulo: Martins Fontes.

Netto, J. P. (2011). Introdução ao estudo do método de Marx. São Paulo: Expressão Popular.

Netto, J. P. (2011b). Introdução ao método da teoria social. Página visitada em 27 de janeiro de 2013 a partir de: http://www.pcb.org.br/portal/docs/int-metodo-teoria-social.pdf

Patto, M. H. de S. (1993). O conceito de cotidianidade em Agnes Heller e a pesquisa em educação. Perspectivas, $16,119-141$.

Rummel, J. F. (1977). Introdução aos procedimentos de pesquisa em Educação (3 ed.). Porto Alegre, RS: Globo.

Saviani, D. (1991). Pedagogia histórico-crítica: primeiras aproximações. Campinas: Autores Associados.

Saviani, D. (2002). Transformações do Capitalismo, do mundo do Trabalho e da Educação. Em: J. C. Lombardi; D. Saviani \& J. L. Sanfelice (Orgs.). Capitalismo, Trabalho e Educação (pp. 23-37). Campinas, SP: Autores Associados: HISTEDBR.

Severino, A. J. (2000). Metodologia do Trabalho Científico (21 ed.). São Paulo: Cortez.

Triviños, A. (1995). Introdução à pesquisa em ciências sociais: a pesquisa qualitativa em educação. São Paulo: Atlas.

Vázquez, A. S. (1977). Filosofia da Práxis. Rio de Janeiro: Paz e Terra. 